\title{
Resposta do dendezeiro à adição de nitrogênio e sua influência na população de bactérias diazotróficas
}

\author{
André Vieira de Carvalho(1), Bruno José Rodrigues Alves ${ }^{(2)}$ e Veronica Massena Reis ${ }^{(2)}$
}

${ }^{(1)}$ Rua General Pederneiras, №590, Centro, CEP 45860-000 Canavieiras, BA. E-mail: arvdc@zipmail.com.br (2)Embrapa Agrobiologia, Caixa Postal 74.505, CEP 23851-970 Seropédica, RJ. E-mail: bruno@cnpab.embrapa.br, veronica@cnpab.embrapa.br

\begin{abstract}
Resumo - O dendê (Elaeis guineensis, Jaquim) pode produzir até sete toneladas de óleo por hectare por ano. O óleo vegetal é muito versátil e pode ser usado desde a indústria alimentícia até a produção de biocombustíveis. A planta é capaz de se associar com bactérias diazotróficas que colonizam raízes e caules. O objetivo deste trabalho foi avaliar a resposta à adubação nitrogenada de 17 genótipos de dendê no primeiro ano de cultivo e avaliar a influência da adição do N mineral sobre a população de bactérias diazotróficas, naturalmente presentes nas plântulas de dendezeiro. Foram utilizados potes de plástico completados com 50\% de areia quartzoza e 50\% de horizonte B de um Argissolo Vermelho-Amarelo, série Itaguaí, não esterilizado e extremamente pobre em nitrogênio. A uréia foi aplicada na dosagem de 33,68 $\mathrm{kg} \mathrm{ha}^{-1}$ de $\mathrm{N}$. Na presença do $\mathrm{N}$, todos os genótipos melhoram os parâmetros biométricos, e houve aumento tanto do $\mathrm{N}$ total quanto do $\mathrm{N}$ acumulado. As populações de bactérias diazotróficas não foram influenciadas pela adição desse elemento. Dois genótipos foram selecionados, na presença e ausência de N, respectivamente, C-2001 e La Mé.
\end{abstract}

Termos para indexação: Elaeis guineensis, genótipo, fixação biológica de nitrogênio.

\section{Response of African oil palm to nitrogen addition and its influence on the diazotrophic bacteria population}

\begin{abstract}
African oil palm (Elaeis guineensis, Jaquim) can produce up to 7 tons of oil per hectare per year. The vegetable oil is greatly versatile in its use, since food industry up to the production of fuels favorable to environmental protection. The plant has the potential to be associative with diazotrophic bacteria which colonize the roots and stem. The objective of this work was to evaluate 17 genotypes of $E$. guineensis in response to nitrogen addition and to verify the influence of this nitrogen on the diazotrophic population in an experiment using plastic pots filled with 50\% quartz sand and 50\% of non sterilized Horizon B; Red-Yellow Podzolic Soil series Itaguaí, extremely poor in nitrogen. Urea was used at a dose of $33.68 \mathrm{~kg} \mathrm{ha}^{-1} \mathrm{de} \mathrm{N}$. In the presence of the nitrogen, all genotypes improved biometric parameters, increased total nitrogen and its accumulation. Its addiction did not affect the diazotrophic population. Two genotypes were selected in the presence and absence of nitrogen: C-2001 and La Mé, respectively.
\end{abstract}

Index terms: Elaeis guineensis, genotype, biological nitrogen fixation.

\section{Introdução}

O dendezeiro é uma palmeira originária do Noroeste da África (Guiné-Bissau), e se destaca na agricultura mundial por possuir elevada produtividade de óleo, podendo chegar a mais de sete toneladas por hectare por ano. Conforme relatado por Clay (2003), a produção mundial do óleo de palma, oriundo do fruto dessa palmeira, vem crescendo em números semelhantes aos da soja, sendo mais consumido em mercados orientais como Índia, China e Japão, do que em potenciais mercados consumidores como EUA, Canadá, América do Sul e Comunidade Européia.
O Brasil tem cerca de 70 milhões de hectares adequados para essa cultura, sendo 50 milhões no Estado do Amazonas e 20 milhões no Pará. Essas áreas têm condições de produzir dendê para absorver grandes demandas internas e externas, o que tornaria o Brasil um dos maiores produtores mundiais.

A expectativa em relação à cultura do dendezeiro advém de sua relevância para o cenário energético e ecológico. Boddey (1993) salientou que se 30\% da área desflorestada da Amazônia brasileira fosse utilizada para o plantio dessa palmeira oleaginosa, haveria possibilidade de suprir a demanda diária de 460 mil barris de óleo diesel consumidos no país, com a vantagem de gerar 
empregos para a população daquela região. O óleo combustível gerado pelo dendezeiro é renovável e não contribui para o aumento do efeito estufa. De acordo com Viegas \& Muller (2000), o dendezeiro é o segundo cultivo do mundo em importância na mitigação do efeito estufa, só perdendo para o cultivo de eucalipto.

Um dos fatores de importância no manejo do dendezeiro é o da fertilização da cultura. Segundo Viegas (1993), esta palmeira apresenta grande demanda por nitrogênio, sendo este o segundo elemento mais importante para a cultura. No oitavo ano de vida, por exemplo, um hectare de dendezeiro (143 plantas) pode chegar a acumular cerca de 568,6 kg de $\mathrm{N}$.

A presença de bactérias diazotróficas em palmeiras oleaginosas foi primeiramente relatada por Shamsudim et al. (1995), que observaram a presença de bactérias do gênero Azospirillum sp. associadas ao dendezeiro, em vários tipos de solos da Malásia. Carvalho (1997) confirmou a presença de bactérias diazotróficas em raízes, mesocarpo e endosperma de sementes, além da estipe de materiais genéticos de diferentes regiões produtoras de dendê no Brasil, sendo confirmada a presença de Azospirillum amazonense, Azospirillum brasilense, Azospirillum lipoferum e Herbaspirillum seropedicae.

A prática da fertilização nitrogenada, comum aos plantios de dendezeiro, pode ter influência sobre as populações e a diversidade das bactérias diazotróficas associadas à cultura, embora ainda não existam estudos detalhados sobre o assunto. Com relação a outras culturas, trabalhos sobre a influência da fertilização nitrogenada, nas populações de bactérias diazotróficas, foram relatados em cana-de-açúcar. A cultura da cana é um dos exemplos em que a associação com bactérias diazotróficas permite altos rendimentos, sem a adição de fertilizantes nitrogenados e aparentemente dependente da variedade (Boddey et al., 2003). Em estudos com variedades eficientes para fixação biológica de nitrogênio (FBN), observou-se redução do número de isolados da bactéria Gluconacetobacter diazotrophicus (Cavalcante \& Döbereiner, 1988), a partir de plantas adubadas com doses elevadas de N (Fuentes-Ramírez et al., 1999; Muthukumarasmy et al., 1999; Reis et al., 2000).

O objetivo deste trabalho foi avaliar a resposta à adição de N mineral em 17 genótipos de dendê e a sua influência na população nativa de bactérias diazotróficas.

\section{Material e Métodos}

Foram retiradas as sementes de frutos de plantas adultas de dendezeiros, cultivadas no Campo Experimental da Embrapa Amazônia Ocidental, Manaus, AM, e na Estação Lemos Maia, pertencente ao Centro de Pesquisa do Cacau (Cepec/Ceplac), na cidade de Una, Bahia. As sementes foram secadas ao ar e ficaram armazenadas em sacos, em galpão à temperatura ambiente, por um período de, pelo menos, três meses. A quebra de dormência foi feita por aquecimento em câmara à temperatura de $39^{\circ} \mathrm{C}$, durante 80 dias consecutivos, utilizando bandejas contendo vermiculita, mantidas a $25-30 \%$ de umidade. As sementes demoraram mais 45 dias para estarem na fase ótima de plantio, com a emissão de radicela e primórdio foliar de $3 \mathrm{~cm}$, em média. O lote selecionado para o plantio foi uniformizado para essas medidas.

O experimento foi montado na Embrapa Agrobiologia, em Seropédica, RJ, a $22^{\circ} 46^{\prime} \mathrm{S}$ e $43^{\circ} 41^{\prime} \mathrm{O}$, com altitude de $33 \mathrm{~m}$, sendo o clima classificado como $A_{W}$, segundo Köppen. A coleta destrutiva das plantas ocorreu 363 dias depois do plantio. Os genótipos testados foram subdivididos em dois grupos. O primeiro deles compreendia oito genótipos oriundos da Embrapa Amazônia Ocidental: 401008, 401105, Caiaué (Elaeis oleifera), 400709, C-2301, C-2312, 315616 e C-2001. Neste grupo, à exceção do Caiaué, todos os materiais foram selecionados, sendo considerados melhorados. No segundo grupo, foram testados os genótipos Dura-Deli, Tenera, Dura Comum, Campinhos, Nativo Rio Pardo, Dura Dumpey, La Mé, Yangambi e C-2501 (da Bahia). Neste caso, os genótipos não sofreram nenhum tipo de seleção, sendo representantes locais e não melhorados, e colhidos em duas estações experimentais pertencentes ao Cepec/Ceplac - a Estação Lemos Maia, localizada em Una, e a Estação Experimental Gregório Bondar, em Barrolândia (genótipos La Mé e Yangambi), ambas situadas na Bahia.

Foram utilizados potes contendo $3 \mathrm{~kg}$ da mistura 1:1 ( $\mathrm{v} / \mathrm{v})$ de areia e terra do horizonte B de um Argissolo Vermelho-Amarelo série Itaguaí. Foram adicionados os seguintes produtos ao substrato: cloreto de potássio, $250 \mathrm{mg} \mathrm{dm}^{-3}$; superfosfato simples, $290 \mathrm{mg} \mathrm{dm}^{-3}$; calcário dolomítico, com PRNT de 85\%, $788 \mathrm{mg} \mathrm{dm}^{-3}$; FTE BR-12, $10 \mathrm{mg} \mathrm{dm}^{-3}$. 
Todo esse material foi misturado em betoneira, e peneirado em malha de $6 \mathrm{~mm}$, antes do preenchimento dos potes. O substrato não recebeu qualquer tipo de esterilização, já que todas as plântulas de dendezeiro, procedentes da Amazônia e da Bahia, continham populações de bactérias diazotróficas preexistentes no endosperma e mesocarpo. Sendo assim, não foi necessário efetuar qualquer tipo de inoculação de bactérias diazotróficas. Esses microrganismos estavam colonizando as sementes pré-germinadas e não o solo do experimento, pois a contagem foi feita apenas nas sementes. $\mathrm{O}$ tratamento nitrogenado recebeu uréia na dosagem de $24 \mathrm{mg} \mathrm{dm}^{-3}$ de substrato por semana, durante quatro semanas consecutivas, o que totalizou $33,7 \mathrm{~kg} \mathrm{ha}^{-1} \mathrm{de} \mathrm{N}$. A primeira aplicação de $\mathrm{N}$ mineral aconteceu depois de dez meses (300 dias) do transplante para o substrato. O delineamento experimental foi o de blocos ao acaso, com 12 repetições de cada tratamento. O experimento foi conduzido ao ar livre, sobre uma mesa com altura de $60 \mathrm{~cm}$.

As plantas foram avaliadas quanto aos seguintes parâmetros biométricos: número de folhas fotossinteticamente ativas (verdes e completamente entendidas); diâmetro na região do colo; altura da planta, medida do colo até a inserção do último par de folhas mais novas abertas; área foliar e radicular, por leitura fotométrica (Li-3100 Area Meter, Li-Cor, Inc).

Para avaliação da presença de bactérias diazotróficas nas sementes pré-germinadas (diazotróficos nativos), $1 \mathrm{~g}$ de folíolo, radicela e endosperma (amostra composta de 10 subamostras) foi macerado com $9 \mathrm{~mL}$ de solução salina (1/4 dos sais do meio de cultivo NFb Döbereiner et al., 1995). Ao final do ensaio, foram utilizadas amostras de $10 \mathrm{~g}$ de raízes e parte aérea, maceradas na proporção de $10 \%$ (p/v), em solução salina. As amostras de rizosfera foram obtidas pela retirada de $10 \mathrm{~g}$ de solo aderido às raízes. A seguir, essas amostras foram misturadas com $90 \mathrm{~mL}$ de solução salina e mantidas sob agitação a 150 rpm por 30 minutos, à temperatura ambiente. Cada avaliação constou de quatro repetições compostas. A partir desse extrato de maceração, foram feitas diluições sucessivas $\left(10^{-2}\right.$ até $\left.10^{-6}\right)$. De cada diluição, foram retiradas alíquotas de $0,1 \mathrm{~mL}$, e procedeu-se à inoculação em frascos contendo o meio semi-sólido semi-seletivo JNFb (Döbereiner et al., 1995), com malato como fonte de carbono, sem $\mathrm{N}$ e pH final 5,8. Neste meio crescem, preferencialmente, as bactérias do gênero Herbaspirillum spp. Em seguida, o material foi incubado a $30^{\circ} \mathrm{C}$ por 96 horas.
Depois desse período, foi feita a avaliação do crescimento, por meio da formação de uma película "papel”. Esta se torna visível pela multiplicação da população bacteriana que migra para a superfície do meio de cultivo, e que é característica da presença de bactérias fixadoras de nitrogênio. O número total de células das populações de bactérias diazotróficas foi avaliado com base na técnica do número mais provável (NMP), utilizando a tabela de McCrady (Döbereiner et al., 1995). Os dados populacionais foram transformados em Log do número de células por g de matéria fresca de tecido, ou solo.

A matéria seca das raízes e dos folíolos foi pesada depois da secagem e em seguida foi moída para determinação do teor de N, pelo método descrito por Bremner \& Mulvaney (1982). Os resultados foram analisados estatisticamente e as médias foram comparadas pelo teste de Tukey, a $1 \%$ de probabilidade.

\section{Resultados e Discussão}

As sementes pré-germinadas foram avaliadas quanto às populações de bactérias diazotróficas nativas, capazes de se desenvolver no meio de cultivo utilizado. A análise dos respectivos crescimentos demonstrou variação de 2,48 a 6,51 Log do número de células g-1 de matéria fresca. $\mathrm{O}$ genótipo que apresentou maiores valores no folíolo, radicela e endosperma foi o C-2312. Em todos os genótipos, os maiores valores foram encontrados na radicela. Isto mostra que a semente prégerminada é um dos veículos utilizados pelas bactérias diazotróficas, na manutenção da sua colonização nas plantas de dendê, não sendo necessário realizar inoculação das bactérias diazotróficas, visto que esta população é elevada (um milhão de células por grama de radicela).

No tratamento sem adição de $\mathrm{N}$, verificou-se que o genótipo C-2001 apresentou o melhor comportamento, na maioria dos parâmetros avaliados (Tabela 1). Destaca-se o melhor desempenho do C-2001 no acúmulo de matéria seca de folíolos, semelhante apenas ao genótipo C-2301, mas com 80,7\% mais matéria seca que o genótipo de pior desempenho, o Caiaué (Elaeis oleifera), e 37,6\% a mais que o pior genótipo de Elaeis guineensis, o 401105. Esse ganho refletiu-se no aumento da área foliar do genótipo C-2301, o único a alcançar valor superior a $240 \mathrm{~cm}^{2}$ por planta.

Verificou-se que, com relação às plantas adubadas com $\mathrm{N}$, os oito genótipos responderam da mesma forma 
quanto aos parâmetros: número de folhas fotossinteticamente ativas (NFFA), diâmetro do colo e altura (Tabela 1). Todas as variáveis foram altamente influenciadas pela adição do fertilizante nitrogenado. Semelhante observação foi feita por Pacheco et al. (1985). O genótipo C-2001 destacou-se, principalmente, em relação à produção de área foliar e, em termos absolutos, apresentou os maiores números nas variáveis estudadas. Excetuando-se a produção de folíolos, houve certa uniformidade de resposta em relação à aplicação de $\mathrm{N}$. O genótipo Caiaué, pertencente à outra espécie de dendê, apresentou o menor desempenho nos atributos avaliados. Essa espécie não passou por nenhum tipo de melhoramento genético por cruzamento, e possui crescimento mais lento que a Elaeis guineensis.

$\mathrm{O}$ dendezeiro responde à aplicação de $\mathrm{N}$ mineral (Walker, 1971), porém, a homogeneidade de resposta no desenvolvimento das plantas, depois da adição de $\mathrm{N}$, indica que, pelo menos na fase inicial (primeiro ano de crescimento), a variabilidade genética entre os genótipos de dendê não poderia explicar as diferenças observadas entre as plantas não adubadas. Isso é um forte indicativo de que, sob limitação de N, existem genótipos capazes de se desenvolver melhor, o que poderia ser atribuído à FBN.

A acumulação de $\mathrm{N}$ pelas plantas, sob limitação de $\mathrm{N}$, é um dos indicadores freqüentemente utilizados para discriminar plantas com potencial para FBN (Pinto et al.,
2001; Reis et al., 2001). Na ausência de N, os genótipos com maiores teores deste nutriente nas raízes foram os genótipos 401008 e 401105. Em relação à parte aérea, destacou-se o 400709 , com mais de $1,3 \%$ de $\mathrm{N}$ nos tecidos. Na presença do adubo, o genótipo C-2301 apresentou um teor superior a $0,7 \%$ nas raízes, enquanto o Caiaué, o 400709 e o 401105 exibiram valores superiores a 1,5\% de N nos folíolos, sendo o C-2301, o de menor resposta.

As raízes das plantas do genótipo 401008, sem adição de $\mathrm{N}$, acumularam valores superiores a $125 \mathrm{mg}$ de $\mathrm{N}$ por planta, 30\% superior ao acumulado por C-2301 (Tabela 2). Nos folíolos, o genótipo C-2312 acumulou a maior quantidade de $\mathrm{N}$ na ausência de adubação nitrogenada, sendo 4\% superior ao C-2001. Na presença de N, o genótipo 315116 acumulou 21\% mais $\mathrm{N}$ nas raízes que o C-2301; os genótipos C-2001 e C-2312 foram superiores aos demais, quanto ao acúmulo de $\mathrm{N}$ nos folíolos, chegando a acumular mais de $600 \mathrm{mg}$ de $\mathrm{N}$ durante o período do estudo.

O número de bactérias diazotróficas presentes nas raízes das plantas de dendê, depois de um ano de cultivo, foi variável entre os genótipos estudados (Tabela 3). Quando se suprimiu o N mineral, o número de bactérias diazotróficas nativas nas raízes foi maior nos genótipos 401105, C-2301 e C-2312. No tratamento com N, observou-se que os genótipos 401105 e 400709 apresentaram números populacionais significativos de bactérias diazotróficas nas raízes, mesmo na presença do

Tabela 1. Parâmetros biométricos das plantas de dendê, de genótipos melhorados, 363 dias depois do plantio, com adição e sem adição de nitrogênio ${ }^{(1)}$.

\begin{tabular}{|c|c|c|c|c|c|c|c|c|c|}
\hline \multirow[t]{2}{*}{ Parâmetro } & \multicolumn{9}{|c|}{ Genótipo } \\
\hline & 401008 & 401105 & Caiaué & 400709 & $\mathrm{C}-2301$ & C-2312 & 315116 & C-2001 & CV (\%) \\
\hline & \multicolumn{9}{|c|}{ Sem nitrogênio } \\
\hline NFFA $^{(2)}$ & $3,63 \mathrm{bcd}$ & $2,58 \mathrm{~d}$ & $2,90 \mathrm{~cd}$ & $2,91 \mathrm{~cd}$ & $4,08 \mathrm{ab}$ & $3,45 \mathrm{abc}$ & $2,83 \mathrm{~cd}$ & $4,66 \mathrm{a}$ & 25,62 \\
\hline Diâmetro do colo (cm) & $1,19 b c$ & $1,38 \mathrm{bc}$ & $1,23 \mathrm{c}$ & $1,43 b c$ & $1,90 \mathrm{a}$ & $1,71 \mathrm{ab}$ & $1,58 \mathrm{abc}$ & $1,96 \mathrm{a}$ & 24,16 \\
\hline Altura $(\mathrm{cm})$ & $3,12 \mathrm{abc}$ & $3,37 \mathrm{abc}$ & $2,98 \mathrm{bc}$ & $4,02 \mathrm{a}$ & $2,54 b c$ & $3,16 a b c$ & $4,00 \mathrm{ab}$ & $2,77 \mathrm{bc}$ & 44,69 \\
\hline Massa seca de raízes (g) & $19,20 \mathrm{a}$ & $14,36 \mathrm{bcd}$ & $10,77 d$ & $13,66 \mathrm{~cd}$ & $16,03 \mathrm{bc}$ & $16,53 \mathrm{abc}$ & $18,55 \mathrm{ab}$ & $20,37 \mathrm{a}$ & 26,12 \\
\hline Massa seca de folíolos (g) & $15,18 \mathrm{c}$ & $14,97 \mathrm{c}$ & $11,40 \mathrm{~d}$ & $15,79 \mathrm{c}$ & $20,55 \mathrm{a}$ & $16,91 \mathrm{c}$ & $18,33 b$ & $20,60 \mathrm{a}$ & 29,32 \\
\hline Área radicular $\left(\mathrm{cm}^{2}\right)$ & $58,30 \mathrm{c}$ & $55,30 \mathrm{c}$ & $44,30 \mathrm{c}$ & $64,40 \mathrm{bc}$ & $109,40 \mathrm{a}$ & $77,60 \mathrm{abc}$ & $85,20 \mathrm{ab}$ & $103,60 \mathrm{ab}$ & 40,43 \\
\hline \multirow[t]{2}{*}{ Área foliar $\left(\mathrm{cm}^{2}\right)$} & $93,10 \mathrm{~b}$ & $102,4 \mathrm{~b}$ & $84,64 \mathrm{~b}$ & $104,90 \mathrm{~b}$ & $137,70 \mathrm{~b}$ & $209,70 \mathrm{a}$ & $114,00 \mathrm{~b}$ & $247,60 \mathrm{a}$ & 32,39 \\
\hline & \multicolumn{9}{|c|}{ Com nitrogênio } \\
\hline NFFA & $6,33 \mathrm{a}$ & $5,98 \mathrm{a}$ & $5,00 \mathrm{a}$ & $5,33 \mathrm{a}$ & $5,41 \mathrm{a}$ & $5,50 \mathrm{a}$ & $4,35 \mathrm{a}$ & $6,58 \mathrm{a}$ & 28,28 \\
\hline Diâmetro do Colo $(\mathrm{cm})$ & $2,28 \mathrm{a}$ & $2,40 \mathrm{a}$ & $1,85 \mathrm{a}$ & $2,36 \mathrm{a}$ & $2,49 \mathrm{a}$ & $2,46 a$ & $2,18 \mathrm{a}$ & $2,56 a$ & 26,30 \\
\hline Altura $(\mathrm{cm})$ & $8,25 \mathrm{a}$ & $8,19 \mathrm{a}$ & $6,85 \mathrm{a}$ & $7,66 \mathrm{a}$ & $7,00 \mathrm{a}$ & $6,41 \mathrm{a}$ & $7,61 \mathrm{a}$ & $6,52 \mathrm{a}$ & 29,91 \\
\hline Massa seca de raízes (g) & $34,65 \mathrm{c}$ & $27,83 \mathrm{e}$ & $21,75 f$ & $29,87 \mathrm{c}$ & $30,42 d$ & $35,09 \mathrm{bc}$ & $38,56 b$ & $39,59 a$ & 47,08 \\
\hline Massa seca de folíolos (g) & $37,60 \mathrm{~b}$ & $34,61 b c$ & $21,90 \mathrm{~d}$ & $23,55 \mathrm{~d}$ & $32,27 \mathrm{c}$ & $30,24 \mathrm{c}$ & $33,00 \mathrm{bc}$ & $48,23 \mathrm{a}$ & 35,54 \\
\hline Área radicular $\left(\mathrm{cm}^{2}\right)$ & $187,70 \mathrm{a}$ & $150,50 \mathrm{a}$ & $108,90 \mathrm{a}$ & $140,40 \mathrm{a}$ & $175,50 \mathrm{a}$ & $186,60 \mathrm{a}$ & $126,10 \mathrm{a}$ & $175,10 \mathrm{a}$ & 41,44 \\
\hline Área foliar $\left(\mathrm{cm}^{2}\right)$ & $419,60 \mathrm{ab}$ & $373,60 \mathrm{~b}$ & $291,30 \mathrm{~b}$ & $377,30 \mathrm{~b}$ & $463,30 \mathrm{ab}$ & $480,70 \mathrm{ab}$ & $273,80 \mathrm{~b}$ & $642,10 \mathrm{a}$ & 39,01 \\
\hline
\end{tabular}

(1) Valores médios de 12 plantas por tratamento; médias seguidas por letras iguais, nas linhas, não diferem entre si a 1\% de probabilidade pelo teste de Tukey. ${ }^{(2) N F F A: ~ n u ́ m e r o ~ d e ~ f o l h a s ~ f o t o s s i n t e t i c a m e n t e ~ a t i v a s . ~}$ 
fertilizante. O genótipo que apresentou maior redução de número de bactérias diazotróficas na presença do $\mathrm{N}$ mineral foi o 401008.

O N mineral aumentou a população de bactérias diazotróficas em cinco genótipos: C-2001, 315116, 400709, 401115 e 401008. No dendezeiro, a hipótese é que este incremento está relacionado à dosagem utilizada, que não foi suficiente para inibir a população de bactérias diazotróficas. Também foi observado que a população destas bactérias diminuiu, em virtude da presença significativa de $\mathrm{N}$ mineral, no C-2301.

Nos folíolos, em presença de N (Tabela 3), a população de bactérias diazotróficas foi menor que nas raízes e no solo rizosférico, para os genótipos 401105, 400709 e C-2312. A quantificação da população de bactérias diazotróficas do solo rizosférico de 401008, Caiaué, C-2301 e 315116 expressaram maior resposta à adição do $\mathrm{N}$ mineral que os demais genótipos (Tabela 3). As populações de bactérias diazotróficas encontradas nos genótipos 401105, 400709, C-2312 e C-2001 apresentaram pouca resposta ao $\mathrm{N}$ mineral. Embora o meio de cultivo seja descrito como semi-seletivo para o isolamento de bactérias do gênero Herbaspirillum spp., a identificação do grupo de bactérias capazes de utilizar o meio de cultivo selecionado não foi realizada e, neste meio, podem se desenvolver mais de uma espécie já descrita como diazotrófica, além de outras não identificadas. Desta forma, não é possível assegurar que a população seja exclusivamente de bactérias pertencentes ao gênero Herbaspirillum.

O crescimento bacteriano, observado no meio de cultivo utilizado, demonstrou que, nas sementes pré-germinadas do segundo grupo de genótipos, também ocorreu uma variação no número populacional das bactérias diazotróficas. Esta variação foi da ordem de 2,47 a 6,80 Log do número de células $\mathrm{g}^{-1}$ de matéria fresca e, como no primeiro grupo anterior, a maior população foi encontrada na radicela. Neste grupo, não houve um genótipo que se destacasse quanto ao número de bactérias diazotróficas encontradas no meio de cultivo.

O genótipo La Mé destacou-se principalmente pela massa de matéria seca de raízes, $58 \%$ superior ao Tenera, que é plantado comercialmente para a produção de óleo. Também produziu 115\% mais massa de matéria seca de folíolos que o genótipo com pior

Tabela 2. Teor de $\mathrm{N}$ e $\mathrm{N}$ total acumulado nos tecidos de raízes e parte aérea (folíolos) de genótipos de dendê melhorados ou não, com adição e sem adição de $\mathrm{N}$ mineral, 363 dias depois do plantio(1).

\begin{tabular}{|c|c|c|c|c|c|c|c|c|}
\hline \multirow[t]{3}{*}{ Genótipos } & \multicolumn{4}{|c|}{ Teor de nitrogênio (\%) } & \multicolumn{4}{|c|}{$\mathrm{N}$ total acumulado (mg planta ${ }^{-1}$ ) } \\
\hline & \multicolumn{2}{|c|}{ Raízes } & \multicolumn{2}{|c|}{ Folíolos } & \multicolumn{2}{|c|}{ Raízes } & \multicolumn{2}{|c|}{ Folíolos } \\
\hline & $-\mathrm{N}$ & $+\mathrm{N}$ & $-\mathrm{N}$ & $+\mathrm{N}$ & $-\mathrm{N}$ & $+\mathrm{N}$ & $-\mathrm{N}$ & $+\mathrm{N}$ \\
\hline \multicolumn{9}{|l|}{ Melhorados } \\
\hline 401008 & $0,67 \mathrm{a}$ & $0,60 \mathrm{~cd}$ & $1,0 \mathrm{de}$ & $1,41 \mathrm{c}$ & $126,12 \mathrm{a}$ & $210,5 b c$ & $153,1 \mathrm{f}$ & $485,0 \mathrm{e}$ \\
\hline 401105 & $0,67 \mathrm{a}$ & $0,70 \mathrm{a}$ & $1,24 b$ & $1,52 \mathrm{a}$ & $95,48 \mathrm{bc}$ & $193,3 \mathrm{~cd}$ & $185,4 \mathrm{~d}$ & $529,1 \mathrm{c}$ \\
\hline Caiaué & $0,50 \mathrm{~cd}$ & $0,53 \mathrm{e}$ & $1,02 \mathrm{~d}$ & $1,54 \mathrm{a}$ & $68,68 \mathrm{~d}$ & $116,9 \mathrm{f}$ & $116,0 \mathrm{~g}$ & $338,0 \mathrm{~h}$ \\
\hline 400709 & $0,50 \mathrm{~cd}$ & $0.64 \mathrm{c}$ & $1.36 \mathrm{a}$ & $1.54 \mathrm{a}$ & $83,77 \mathrm{c}$ & $192.9 \mathrm{~cd}$ & $215,0 \mathrm{~d}$ & $476,3 \mathrm{f}$ \\
\hline C-2301 & $0,60 \mathrm{~b}$ & $0,71 \mathrm{a}$ & $0,87 f$ & $1,19 \mathrm{f}$ & $96,71 \mathrm{~b}$ & $213,3 b$ & $183,1 \mathrm{e}$ & $511,8 \mathrm{~d}$ \\
\hline $\mathrm{C}-2312$ & $0,45 \mathrm{e}$ & $0,47 f$ & $1,09 \mathrm{c}$ & $1,27 \mathrm{e}$ & $93,01 \mathrm{bc}$ & $186,9 \mathrm{~d}$ & $234,5 a$ & $663,3 b$ \\
\hline 315116 & $0,44 \mathrm{e}$ & $0,67 \mathrm{~b}$ & $1,21 \mathrm{~b}$ & $1,34 \mathrm{~d}$ & $82,92 \mathrm{~cd}$ & $258,4 \mathrm{a}$ & $224,4 \mathrm{c}$ & $445,5 \mathrm{~g}$ \\
\hline C-2001 & $0,52 \mathrm{c}$ & $0,62 d$ & $0,99 \mathrm{e}$ & $1,44 b$ & $56,48 \mathrm{~d}$ & $156,11 \mathrm{e}$ & $225,1 \mathrm{~b}$ & $695,6 \mathrm{a}$ \\
\hline $\mathrm{CV}(\%)$ & 7,54 & 8,56 & 8,98 & 10,69 & 6,90 & 4,49 & 13,63 & 10,39 \\
\hline \multicolumn{9}{|l|}{ Não melhorados } \\
\hline C-2501 & $0,91 \mathrm{c}$ & $1,59 b$ & $2,41 \mathrm{a}$ & $3,00 \mathrm{a}$ & $67,88 \mathrm{~b}$ & $132,01 \mathrm{abc}$ & $131,81 \mathrm{ab}$ & $222,0 \mathrm{~cd}$ \\
\hline Dura-Deli & $0,51 \mathrm{~g}$ & $1,36 \mathrm{c}$ & $1,96 \mathrm{c}$ & $2,21 \mathrm{e}$ & $25,88 \mathrm{~g}$ & $161,8 \mathrm{ab}$ & $161,2 \mathrm{a}$ & $216,5 \mathrm{~d}$ \\
\hline La Mé & $0,48 \mathrm{~g}$ & $1,14 \mathrm{e}$ & $1,47 \mathrm{~d}$ & $2,35 \mathrm{~d}$ & $50,88 \mathrm{de}$ & $155,21 \mathrm{ab}$ & $129,87 \mathrm{abc}$ & $271,3 b$ \\
\hline Yamgambi & $0,43 \mathrm{~h}$ & $0,58 \mathrm{~g}$ & $1,54 \mathrm{~d}$ & $2,11 \mathrm{e}$ & $45,58 \mathrm{f}$ & $56,23 \mathrm{c}$ & $82,80 \mathrm{bc}$ & $154,0 \mathrm{e}$ \\
\hline Dura Dumpey & $0,88 \mathrm{~d}$ & $0,78 \mathrm{f}$ & $2,01 \mathrm{~b}$ & $2,21 \mathrm{e}$ & $62,82 \mathrm{c}$ & $65,55 \mathrm{bc}$ & $87,40 \mathrm{bc}$ & $157,1 \mathrm{e}$ \\
\hline Dura Comum & $0,55 \mathrm{f}$ & $1,33 \mathrm{~cd}$ & $1,47 \mathrm{~d}$ & $2,13 \mathrm{e}$ & $48,40 \mathrm{e}$ & $179,60 \mathrm{a}$ & $145,51 \mathrm{a}$ & $328,4 a$ \\
\hline Tenera & $0,97 b$ & $1,55 \mathrm{~b}$ & $1,91 \mathrm{c}$ & $2,54 \mathrm{c}$ & $64,99 \mathrm{c}$ & $119,4 \mathrm{abc}$ & $131,89 b$ & $236,3 \mathrm{c}$ \\
\hline Nativo Rio Pardo & $0,77 \mathrm{e}$ & $1,71 \mathrm{a}$ & $1,51 \mathrm{~d}$ & $2,8 \mathrm{~b}$ & $52,36 \mathrm{~d}$ & $133,4 \mathrm{abc}$ & $133,0 \mathrm{ab}$ & $173,6 \mathrm{e}$ \\
\hline Campinhos & $1,24 \mathrm{a}$ & $1,24 \mathrm{~d}$ & $2,11 \mathrm{~b}$ & $2,76 \mathrm{~b}$ & $76,85 \mathrm{a}$ & $109,1 \mathrm{bc}$ & $75,59 \mathrm{c}$ & $165,5 \mathrm{e}$ \\
\hline CV $(\%)$ & 12,32 & 11,91 & 12,41 & 10,16 & 11,71 & 31,03 & 31,83 & 16,37 \\
\hline
\end{tabular}

(1)Valores médios de 12 repetições; médias seguidas por letras iguais, nas colunas, não diferem entre si a 1\% de probabilidade pelo teste de Tukey; -N: sem adição de nitrogênio mineral; +N: com adição de nitrogênio mineral. 
desempenho, o Campinhos, e $32 \%$ a mais que o Dura-Deli. Neste ensaio, em que se utilizaram materiais que não sofreram cruzamentos para obtenção de

Tabela 3. Número populacional de bactérias diazotróficas presentes no meio de cultivo JNFb, a partir de amostras de raízes, folíolos e no solo, de genótipos de dendê melhorados ou não, adubados ou não com $\mathrm{N}$ mineral, aos 363 dias depois do plantio $^{(1)}$.

\begin{tabular}{|c|c|c|c|c|c|c|}
\hline \multirow[t]{3}{*}{ Genótipos } & \multicolumn{6}{|c|}{ Log do número de células $\mathrm{g}^{-1}$ de matéria fresca } \\
\hline & \multicolumn{2}{|c|}{ Raízes } & \multicolumn{2}{|c|}{ Folíolos } & \multicolumn{2}{|c|}{ Solo rizosférico } \\
\hline & $-\mathrm{N}$ & $+\mathrm{N}$ & $-\mathrm{N}$ & $+\mathrm{N}$ & $-\mathrm{N}$ & $+\mathrm{N}$ \\
\hline \multicolumn{7}{|l|}{ Melhorados } \\
\hline 401008 & $5,00 \mathrm{ab}$ & $5,24 \mathrm{~b}$ & $4,65 \mathrm{a}$ & $2,47 \mathrm{ab}$ & $3,73 \mathrm{a}$ & $2,03 b$ \\
\hline 401105 & $7,10 \mathrm{a}$ & $7,14 a$ & $3,27 \mathrm{ab}$ & $0,13 b$ & $4,29 \mathrm{a}$ & $5,03 \mathrm{a}$ \\
\hline Caiaué & $6,38 \mathrm{ab}$ & $6,27 \mathrm{ab}$ & $3,25 \mathrm{ab}$ & $4,57 \mathrm{a}$ & $3,07 \mathrm{a}$ & $1,49 \mathrm{~b}$ \\
\hline 400709 & $4,72 \mathrm{ab}$ & $7,14 a$ & $2,91 \mathrm{ab}$ & $2,67 \mathrm{ab}$ & $3,12 \mathrm{a}$ & $3,21 a b$ \\
\hline $\mathrm{C}-2301$ & $7,00 \mathrm{a}$ & $5,74 \mathrm{ab}$ & $2,47 b$ & $0,65 b$ & $3,67 \mathrm{a}$ & $0,12 \mathrm{~b}$ \\
\hline $\mathrm{C}-2312$ & $7,14 \mathrm{a}$ & $6,32 \mathrm{ab}$ & $2,47 \mathrm{~b}$ & $2,47 \mathrm{ab}$ & $1,25 \mathrm{a}$ & $3,97 \mathrm{ab}$ \\
\hline 315116 & $4,51 \mathrm{ab}$ & $6,37 \mathrm{ab}$ & $2,53 \mathrm{~b}$ & $1,69 \mathrm{~b}$ & $3,67 \mathrm{a}$ & $1,25 \mathrm{~b}$ \\
\hline C-2001 & $4,06 \mathrm{~b}$ & $5,77 \mathrm{ab}$ & $2,47 b$ & $2,13 \mathrm{~b}$ & $3,89 \mathrm{a}$ & $3,81 \mathrm{ab}$ \\
\hline $\mathrm{CV}(\%)$ & 12,48 & 11,02 & 27,45 & 25,91 & 18,44 & 20,54 \\
\hline \multicolumn{7}{|l|}{ Não melhorados } \\
\hline C-2501 & $6,27 \mathrm{ab}$ & $6,20 \mathrm{ab}$ & $5,38 \mathrm{a}$ & $7,14 \mathrm{a}$ & $6,03 \mathrm{ab}$ & $6,71 \mathrm{a}$ \\
\hline Dura-Deli & $6,77 \mathrm{a}$ & $6,91 \mathrm{a}$ & $2,72 b c$ & $3,13 \mathrm{~b}$ & $5,51 \mathrm{ab}$ & $6,78 \mathrm{a}$ \\
\hline LaMé & $6,57 \mathrm{ab}$ & $5,2 \mathrm{ab}$ & $4,42 \mathrm{abc}$ & $3,69 b$ & $6,23 \mathrm{ab}$ & $5,42 \mathrm{a}$ \\
\hline Yamgambi & $4,52 \mathrm{c}$ & $3,63 b$ & 2,71abc & $3,05 \mathrm{~b}$ & $4,76 b$ & $4,28 \mathrm{a}$ \\
\hline Dura Dumpey & $5,76 \mathrm{abc}$ & $5,94 \mathrm{ab}$ & $4,80 \mathrm{ab}$ & $5,99 \mathrm{a}$ & $6,51 \mathrm{a}$ & $6,45 \mathrm{a}$ \\
\hline Dura Comum & $4,79 \mathrm{bc}$ & $5,11 \mathrm{ab}$ & $2,72 b c$ & $5,92 \mathrm{ab}$ & $4,21 \mathrm{~b}$ & $5,06 \mathrm{a}$ \\
\hline Tenera & $5,86 \mathrm{abc}$ & $5,69 \mathrm{ab}$ & $2,60 \mathrm{c}$ & $3,81 \mathrm{~b}$ & $6,17 \mathrm{ab}$ & $5,5 \mathrm{a}$ \\
\hline Nat.Rio Pardo & $6,44 a b$ & $6,38 \mathrm{a}$ & $4,51 \mathrm{abc}$ & $4,40 \mathrm{ab}$ & $5,00 \mathrm{~b}$ & $4,51 \mathrm{a}$ \\
\hline Campinhos & $6,54 \mathrm{ab}$ & $6,27 \mathrm{a}$ & $3,31 \mathrm{abc}$ & $3,53 \mathrm{~b}$ & $5,71 \mathrm{ab}$ & $5,91 \mathrm{a}$ \\
\hline $\mathrm{CV} \%$ & 16,78 & 19,56 & 31,50 & 23,50 & 27,91 & 24,34 \\
\hline
\end{tabular}

(1)Valores médios de 4 repetições; médias seguidas por letras iguais, nas colunas, não diferem entre si a $1 \%$ de probabilidade pelo teste de Tukey; -N: sem adição de nitrogênio mineral; +N: com adição de nitrogênio mineral. genótipos mais produtivos e de diversas origens, verificou-se menor variabilidade, resultando em menor diferenciação da resposta ao plantio com adição e sem adição de fertilizante nitrogenado.

Na presença de $\mathrm{N}$, destacaram-se os genótipos Dura Comum e La Mé, com produção de mais de $10 \mathrm{~g}$ de folíolos secos (Tabela 4). O genótipo Dura Comum acumulou 34\% mais massa seca de folíolos do que o La Mé, mostrando um incremento de $220,8 \%$ sobre a acumulação na ausência de $\mathrm{N}$ mineral. Com relação ao acúmulo de matéria seca de raízes, estes foram os únicos genótipos a produzirem mais de $13 \mathrm{~g}$, correspondendo quase ao dobro de massa, quando comparado a Nativo Rio Pardo (7,66 g). Entretanto, se comparados os dois grupos de genótipos, observa-se que o material oriundo da Embrapa Amazônia Ocidental foi mais eficiente na produção de matéria seca de folíolos, acumulando valores superiores a $23,5 \mathrm{~g}$, pelo período de um ano de cultivo.

Com relação ao parâmetro área radicular produzida pelos diferentes genótipos ao final do ensaio (Tabela 4), verificouse que, na ausência do N mineral, o genótipo Dura Dumpey apresentou o maior valor, sendo 26\% superior ao La Mé, embora não tenha diferido estatisticamente. Entretanto, esse aumento não refletiu na massa de matéria seca de raízes. Na presença de N, novamente destacou-se o La Mé, que chegou a possuir uma área radicular $118 \%$ superior à do Campinhos - pior genótipo, quanto a essa característica.

Tabela 4. Parâmetros biométricos das plantas de dendê, de genótipos não melhorados, 363 dias depois do plantio, com e sem adição de nitrogênio ${ }^{(1)}$.

\begin{tabular}{|c|c|c|c|c|c|c|c|c|c|c|}
\hline \multirow[t]{2}{*}{ Parâmetro } & \multicolumn{10}{|c|}{ Genótipo } \\
\hline & C-2501 & Dura-Deli & La Mé Y & Yangambi & $\begin{array}{c}\text { Dura } \\
\text { Dumpey }\end{array}$ & $\begin{array}{c}\text { Dura } \\
\text { Comum }\end{array}$ & Tenera & $\begin{array}{c}\text { Nativo } \\
\text { Rio Pardo }\end{array}$ & Campinhos & $\begin{array}{l}\text { CV } \\
(\%)\end{array}$ \\
\hline & \multicolumn{10}{|c|}{ Sem nitrogênio } \\
\hline NFFA $^{(2)}$ & $4,35 \mathrm{a}$ & $5,18 \mathrm{a}$ & $5,33 \mathrm{a}$ & $4,91 \mathrm{a}$ & $3,34 \mathrm{a}$ & $4,25 \mathrm{a}$ & $4,34 \mathrm{a}$ & $4,37 \mathrm{a}$ & $5,22 \mathrm{a}$ & 30,50 \\
\hline Diâmetro & $1,19 \mathrm{ab}$ & $1,57 \mathrm{ab}$ & $1,50 \mathrm{ab}$ & & $1,11 b$ & $1,48 \mathrm{ab}$ & & $1,64 \mathrm{a}$ & & 32,52 \\
\hline Alture & $2,23 b$ & $4,25 \mathrm{ab}$ & $4,92 \mathrm{ab}$ & $5,66 \mathrm{ab}$ & $4,06 a b$ & & & $3,76 a b$ & & 33,06 \\
\hline Mass & $7,46 a$ & $9,99 a$ & $10,60 \mathrm{a}$ & $6,70 \mathrm{a}$ & $7,10 \mathrm{a}$ & 8,8 & 6,7 & $6,80 \mathrm{a}$ & & 41,92 \\
\hline Mas & $5,70 \mathrm{ab}$ & $7,50 \mathrm{ab}$ & $9,90 \mathrm{a}$ & $5,80 \mathrm{ab}$ & $5,80 \mathrm{ab}$ & $4,80 \mathrm{~b}$ & $5,20 \mathrm{ab}$ & $4,70 \mathrm{~b}$ & $4,60 \mathrm{~b}$ & 35,47 \\
\hline Área radicular ( $\mathrm{cn}$ & $40,42 \mathrm{~b}$ & $54,15 \mathrm{ab}$ & $57,6 \mathrm{ab}$ & $36,71 \mathrm{~b}$ & $72,72 a$ & $48,01 \mathrm{~b}$ & $36,66 \mathrm{~b}$ & $36,69 \mathrm{~b}$ & $47,92 \mathrm{~b}$ & 41,92 \\
\hline \multirow[t]{2}{*}{ Área foliar $\left(\mathrm{cm}^{2}\right)$} & $63,99 d$ & $84,38 \mathrm{a}$ & $77,71 \mathrm{~b}$ & $65,15 \mathrm{c}$ & $65,06 \mathrm{c}$ & $55,74 \mathrm{ef}$ & $59,08 \mathrm{e}$ & $52,42 \mathrm{fg}$ & $51,80 \mathrm{~g}$ & 35,02 \\
\hline & \multicolumn{10}{|c|}{ Com nitrogênio } \\
\hline NFFA & $5,11 \mathrm{ab}$ & $5,76 \mathrm{a}$ & $5,75 \mathrm{a}$ & $6,07 \mathrm{a}$ & $3,68 \mathrm{~b}$ & $5,33 \mathrm{ab}$ & 5,1 & $4,82 \mathrm{al}$ & & 35,67 \\
\hline Diâmetro & $1,39 \mathrm{ab}$ & $2,06 \mathrm{a}$ & $1,90 \mathrm{ab}$ & $2,04 \mathrm{a}$ & $1,26 a b$ & $1,92 \mathrm{ab}$ & $1,64 \mathrm{ab}$ & $1,98 \mathrm{ab}$ & $1,68 b$ & 29,60 \\
\hline Altura $(\mathrm{cm})$ & $5,24 \mathrm{ab}$ & $6,94 a$ & $7,12 \mathrm{a}$ & $6,07 \mathrm{de}$ & $5,82 \mathrm{f}$ & $6,37 \mathrm{~d}$ & $6,20 \mathrm{e}$ & $5,27 \mathrm{~g}$ & $6,41 \mathrm{c}$ & 32,85 \\
\hline Massa seca d & $8,42 \mathrm{e}$ & $12,06 \mathrm{bc}$ & $13,09 \mathrm{ab}$ & $9,60 \mathrm{~d}$ & $8,41 \mathrm{e}$ & $13,72 \mathrm{a}$ & $7,93 \mathrm{e}$ & $7,66 \mathrm{e}$ & $11,29 \mathrm{c}$ & 44,17 \\
\hline Massa se & $7,40 \mathrm{~d}$ & $9,80 \mathrm{c}$ & $11,50 \mathrm{~b}$ & $7,30 \mathrm{~d}$ & $7,10 \mathrm{~d}$ & $15,40 \mathrm{a}$ & $9,30 \mathrm{c}$ & $6,20 \mathrm{~d}$ & $6,00 \mathrm{~d}$ & 48,07 \\
\hline Área radicular $\left(\mathrm{cm}^{2}\right)$ & $45,25 \mathrm{abc}$ & $65,46 \mathrm{ab}$ & $74,34 \mathrm{a}$ & $52,55 \mathrm{ab}$ & $42,59 \mathrm{bc}$ & $68,92 \mathrm{ab}$ & $42,15 b c$ & $42,63 \mathrm{bc}$ & $34,08 \mathrm{c}$ & 44,67 \\
\hline Área foliar $\left(\mathrm{cm}^{2}\right)$ & $82,82 \mathrm{ab}$ & $109,70 \mathrm{ab}$ & $129,10 \mathrm{ab}$ & $82,46 \mathrm{ab}$ & $79,69 \mathrm{ab}$ & $171,70 \mathrm{a}$ & $103,7 \mathrm{ab}$ & $70,17 \mathrm{~b}$ & $67,41 \mathrm{~b}$ & 47,64 \\
\hline
\end{tabular}

${ }^{(1)}$ Valores médios de 12 plantas por tratamento; médias seguidas por letras iguais, nas linhas, não diferem entre si a $1 \%$ de probabilidade pelo teste de Tukey. ${ }^{(2) N F F A: ~ n u ́ m e r o ~ d e ~ f o l h a s ~ f o t o s s i n t e t i c a m e n t e ~ a t i v a s . ~}$ 
Este parâmetro é relevante por relacionar-se à resistência a estresses, principalmente hídricos. Quanto à área foliar, na ausência do fertilizante nitrogenado, destacou-se o genótipo Dura-Deli, apresentando um valor $50 \%$ superior à do Campinhos, de pior desempenho. $\mathrm{Na}$ presença do $\mathrm{N}$ mineral, o genótipo Dura Comum produziu o maior valor de área foliar, acima de $170 \mathrm{~cm}^{2}$, embora não superior à de outros genótipos por causa da variabilidade.

Quanto ao teor de $\mathrm{N}$ nas raízes de mudas de dendezeiro, ao final do ensaio (Tabela 2), verificou-se que, sem adição de $\mathrm{N}$, o genótipo Campinhos se destacou, e atingiu mais de 1,2\% de $\mathrm{N}$ nas raízes, refletindo baixo rendimento de biomassa. Já o Nativo Rio Pardo respondeu à presença do fertilizante nitrogenado neste parâmetro nutricional, inversamente ao genótipo Yangambi, embora com valores semelhantes de matéria seca (Tabela 4).

$\mathrm{O}$ genótipo que mais respondeu à presença do $\mathrm{N}$ mineral, em relação ao conteúdo de $\mathrm{N}$ total nas raízes de dendezeiro, foi o Nativo Rio Pardo. Quanto ao nitrogênio acumulado, os genótipos Dura Comum, Dura-Deli, e La Mé acumularam mais de 150 mg de N nas raízes. Avaliou-se, também, o teor de $\mathrm{N}$ nos folíolos, ao final do ensaio (Tabela 2). O C-2501 expressou o melhor resultado, tanto na presença do adubo nitrogenado quanto na sua ausência. Entre os genótipos que não evidenciaram resposta ao fertilizante nitrogenado, na melhoria desta variável nutricional, destaca-se o Yangambi. Com relação ao $\mathrm{N}$ total acumulado nos folíolos, ao final do estudo, constatou-se que, sem adição de N, os genótipos de dendê Dura-Deli, seguido dos genótipos Dura Comum, Nativo Rio Pardo, Tenera e C-2501 acumularam mais de $130 \mathrm{mg}$ de $\mathrm{N}$ por planta e, com adição de $\mathrm{N}$, o mais eficiente foi o genótipo Dura Comum (Tabela 2).

Quanto à contagem das bactérias diazotróficas nas raízes, parte aérea e solo rizosférico (meio JNFb), não foi observado padrão de resposta no comportamento populacional em virtude da adição do fertilizante nitrogenado (Tabela 3).

Os genótipos de dendê produzidos pela Embrapa Amazônia Ocidental apresentaram melhor resposta à adição de $\mathrm{N}$, maior acúmulo de biomassa e menor variabilidade entre as plantas, mostrando que o programa de melhoramento tem avançado na seleção de plantas de crescimento mais rápido, mesmo em condições de estresse. O material, proveniente das duas Estações Experimentais, pertencentes ao Ceplac, apresentou comportamento semelhante ao de E. oleifera (Caiaué). Esses genótipos não sofreram cruzamento para obten- ção de plantas mais produtivas e, nesse caso, as plantas apresentaram maior variabilidade de resposta, consistindo em uma fonte genética que pode ser mais profundamente explorada, quanto à dependência da FBN.

Em virtude da forte representatividade econômica da cultura do dendê, programas de melhoramento podem dar origem a genótipos mais eficientes no uso de nutrientes que beneficiem o crescimento e com maior produtividade.

Apenas quatro espécies de palmeiras foram domesticadas - coco, pupunha, tâmara e dendê - de um universo de 3 mil espécies, pertencentes à família das Arecaceae (Reis et al., 2000). O melhoramento do dendê tem cerca de 50 anos e para se obter um genótipo, o processo de seleção leva de 10 a 12 anos, além de requerer área experimental extensa (Purba et al., 2001).

Tentativas de caracterização genética de 723 acessos dessa espécie foram realizadas por Hayati et al. (2004). Em dois trabalhos de obtenção de genótipos melhorados de dendê, foi observado que o ambiente influencia a performance produtiva desses materiais (Gawankar et al., 2002; Rafii et al., 2002). Estudos também têm mostrado que as progênies testadas nos programas de melhoramento derivam de um número limitado de palmeiras ancestrais. Por exemplo, a subpopulação de La Mé, usada por Purba et al. (2001), na estação de pesquisa sobre dendê na Indonésia, era originária de apenas dois parentais: Brt 10 e Teis 3. Outras duas subpopulações testadas de Yangambi e SP $540 \mathrm{~T}$ tinham como parental uma única palmeira: Djongo. Esses resultados ilustram a dificuldade de se testar materiais genéticos de uma espécie recentemente domesticada, como o dendê.

Atualmente, o mercado de óleo vegetal brasileiro é abastecido por outros óleos, como o de soja, e as quantidades importadas são ainda pequenas e estacionais. O Brasil é um país propício ao cultivo do dendê e o aumento do uso desse óleo como biocombustível deve-se basear em um plano de melhoramento genético para condições de baixa fertilidade, em que se enquadram a maioria dos solos tropicais disponíveis ao seu cultivo.

\section{Conclusões}

1. O genótipo C-2001 e o La Mé são os mais responsivos aos parâmetros avaliados tanto na presença quanto na ausência de nitrogênio.

2. A espécie Elaeis oleifera é a que menos respondeu à adição de fertilizante nitrogenado. 
3. A influência da adição de nitrogênio sobre a população de bactérias diazotróficas é bastante variável entre os genótipos testados, e partes das plantas avaliadas não apresentam tendência clara de inibição ou de estímulo.

\section{Agradecimentos}

Ao CNPq, pela bolsa de doutorado concedida ao primeiro autor; ao pesquisador Edson Barcelos, da Embrapa Amazônia Ocidental, pelas sugestões dadas e envio de parte dos materiais testados; ao pesquisador José Inácio, da Estação Experimental Lemos Maia, Una - Cepec/ Ceplac, BA, pelo envio de materiais da região.

\section{Referências}

BODDEY, R.M. Green energy from sugar cane. Chemistry and Industry, v.12, p.355-358, 1993.

BODDEY, R.M.; URQUIAGA, S.; ALVES, B.J.R.; REIS, V.M. Endophytic nitrogen fixation in sugarcane: present knowledge and future applications. Plant and Soil, v.252, p.139-149, 2003.

BREMNER, J.M.; MULVANEY, C.S. Nitrogen total. In: PAGE, A.L.; MILLER, R.H.; KEENEY, D.R. (Ed.). Methods of soil analysis: part 2, chemical and microbiological properties. Madison: American Society of Agronomy; Soil Science Society of America, 1982. p.595-624.

CARVALHO, A.L.V. Associação de bactérias diazotróficas e fungos micorrízicos arbusculares em mudas de pupunheira (Bactris gasipaes H.B.K.) e de dendezeiro (Elaeis guineensis Jacq.). 1997. 217p. Dissertação (Mestrado) - Universidade Federal Rural do Rio de Janeiro, Seropédica.

CAVALCANTE, V.A.; DÖBEREINER, J. A new acid-tolerant nitrogen-fixing bacterium associated with sugarcane. Plant and Soil, v.108, p.23-31, 1988.

CLAY, J. World agriculture and the environment: a commodityby-commodity guide to impacts and practices. Washington, DC: Island, 2003. 570p.

DÖBEREINER, J.; BALDANI, V.L.D.; BALDANI, J.I. Como isolar e identificar bactérias fixadoras de nitrogênio em não leguminosas. Brasília: Embrapa-SPI; Seropédica: Embrapa-Cnpab, 1995. 60p.

FUENTES-RAMÍREZ, L.E.; CABALLERO-MELLADO, J.; SEPÚLVEDA, J.; MARTÍNEZ-ROMERO, E. Colonization of sugarcane by Acetobacter diazotrophicus is inhibited by high Nfertilization. FEMS Microbiology Ecology, v.29, p.117-128, 1999.

GAWANKAR, M.S.; DEVMORET, J.P.; JAMADAGNI, B.M.; KHAN, H.H. Early performance of oil palm genotypes. Journal of Plantation Crops, v.30, p.44-47, 2002.
HAYATI, A.; WICKNESWARI, R.; MAIZURA, I.; RAJANAIDU, N. Genetic diversity of oil palm (Elaeis guineensis Jacq.) germplasm collections from Africa: implications for improvement and conservation of genetic resources. Theoretical and Applied Genetics, v.108, p.1274-1284, 2004.

MUTHUKUMARASAMY, R.; REVATHI, G.; LAKSHMINARASIMHAN, C. Influence of nitrogen fertilization on the isolation of Acetobacter diazotrophicus and Herbaspirillum spp. from Indian sugarcane varietes. Biology and Fertility of Soils, v.29, p.157-164, 1999.

PACHECO, A.R.; TAILLIEZ, B.J.; SOUZA, R.L.R. de; LIMA, E.J. de. Les deficiciences minerales du palmier à huile (E. guineensis Jacq.) dans la region de Belém, Pará (Bresil). Oleagineux, v.40, p.295-309, 1985.

PINTO, M.G.; BODDEY, R.M.; ALVES, B.J.R.; URQUIAGA, S. Potencial produtivo de 40 genótipos de arroz inundado em solo pobre, sem adição de N. Agronomia, v.35, p.43-46, 2001.

PURBA, A.R.; FLORI, A.; BAUDOUIN, L.; HAMON, S. Prediction of oil palm (Elaeis guineensis, Jacq.) agronomic performances using the best linear umbiased predictor (blup). Theoretical and Applied Genetics, v.102, p.787-792, 2001.

RAFII, M.Y.; RAJANAIDU, N.; JALANI, B.S.; KUSHAIRI, A. Performance and heritability estimations on oil palm progenies tested in different environments. Journal of Oil Palm Research, v.14, p.15-24, 2002.

REIS, V.M.; BALDANI, J.I.; BALDANI, V.L.D.; DÖBEREINER, J. Biological dinitrogen fixation in Gramineae and palm trees. Critical Reviews in Plant Sciences, v.19, p.227-247, 2000.

REIS, V.M.; REIS JUNIOR, F.B. dos; QUESADA, D.M.; OLIVEIRA, O.C.A. de; ALVES, B.J.R.; URQUIAGA, S.; BODDEY, R.M. Biological nitrogen fixation associated with tropical pasture grasses. Australian Journal of Plant Physiology, v.28, p.837844, 2001.

SHAMSUDDIN, Z.H.; MARZIAH, M.; ROHANI, O.; ROSLINA, A.W.; HO, C.N.; NORAZA, H.; CHALK, P.M. Nitrogen fixation by Azospirillum in association with oil palm (Elaeis guineensis Jacq.). In: INTERNATIONAL SYMPOSIUM ON SUSTAINABLE AGRICULTURE FOR THE TROPICS, [1.], 1995, Angra dos Reis, RJ. Anais. Angra dos Reis, RJ: Embrapa-Cnpab, 1995. p. 232-233.

VIEGAS, I. de J.M. Crescimento do dendezeiro (Elaeis guineensis Jacq.); concentração, conteúdo e exportação de nutrientes nas diferentes partes de plantas com 2 a 8 anos de idade, cultivadas em Latossolo Amarelo distrófico, Tailândia, Pará. 1993. 217p. Dissertação (Mestrado) - Escola Superior de Agricultura Luiz de Queiroz, Piracicaba.

VIEGAS, I. de J.M.; MULLER, A.A. A cultura do dendezeiro na Amazônia brasileira. Belém: Embrapa-Cpatu; Manaus: EmbrapaCPAA, 2000. 374p.

WALKER, W.M. Effect of N, P, Mg, K and soils upon oil palm yields in Sierra Leone. Tropical Agriculture, v.48, p.237-243, 1971.

Recebido em 10 de novembro de 2004 e aprovado em 8 de junho de 2005 